\title{
La visión crítica del pragmatismo ambiental respecto a la ética ambiental tradicional
}

\author{
Víctor Hugo Salazar Ortiz \\ Departamento de Filosofía \\ Universidad Autónoma de Aguascalientes \\ vhsalaza@correo.uaa.mx
}

\section{Antropocentrismo ambiental tradicional}

Durante las tres últimas décadas del siglo pasado, y lo que va del presente, han tratado de enfatizarse, por diferentes medios, los compromisos morales ${ }^{1}$ que tenemos como especie hacia el mundo natural. Éstos surgen a partir de la toma de conciencia de que los sistemas naturales que sostienen a nuestro planeta, así como la biodiversidad, se han venido atrofiando como consecuencia de la excesiva explotación

\footnotetext{
1 En diversos tratados y programas internacionales relativos al medio ambiente (por ejemplo, «Conferencia de Estocolmo», «La cumbre de la tierra Río 92», «Johannesburgo 2002» y «Río+20») se emplea un lenguaje moral, pues se hace referencia a la necesidad de generar principios por medio de los cuales se tome una mayor conciencia de nuestra responsabilidad y de nuestras obligaciones hacia el mundo natural. Se esperaría con ello una modificación de nuestro comportamiento y nuestras actitudes ambientales. No se dice explícitamente que tengamos "compromisos morales», pero de acuerdo con lo que digo, claramente pueden suscribirse los conceptos referidos dentro de un lenguaje moral.
} 
de los «bienes ecológicos» ${ }^{2}$, y del constante vertimiento de sustancias contaminantes en el aire, agua y suelos.

Los desajustes de los ciclos naturales en los ecosistemas han sido provocados por diversos factores antropogénicos ${ }^{3}$, como son: 1) el descontrolado crecimiento demográfico de nuestra especie ${ }^{4}$, lo cual ha implicado a su vez el incremento y satisfacción de nuestras necesidades. Por esta razón, se ha requerido de una mayor cantidad de espacios, que han estado en constante expansión. Esto ha sucedido para que puedan llevarse a cabo las actividades productivas que hacen posible nuestra subsistencia. 2) La contaminación industrial, que es la principal responsable de la emisión de sustancias nocivas a la atmósfera, ríos y mar, o directamente al suelo, lo cual provoca erosión y filtraciones en los mantos acuíferos. 3) La agricultura y la ganadería. Sus métodos de producción promovieron la deforestación, y han provocado el agotamiento y la contaminación a gran escala en agua y suelos. 4) La producción de energía y combustibles fósiles (petróleo, gas y carbón), principales elementos generadores del calentamiento global. Paradójicamente, sin esta expansión, explotación de recursos e impacto ambiental careceríamos de los

\footnotetext{
2 Generalmente se llaman recursos naturales a los suministros que los seres humanos obtenemos de la naturaleza; sin embargo, utilizaré bienes ecológicos para referirme a éstos, siguiendo la sugerencia que hace la Dra. Leonora Esquivel en su tesis doctoral (ver 2006; 195-198).

3 «El término antropogénico se refiere a los efectos, procesos o materiales que son el resultado de actividades humanas a diferencia de los que tienen causas naturales sin influencia humana. Normalmente se usa para describir contaminaciones ambientales en forma de desechos químicos o biológicos como consecuencia de las actividades económicas, tales como la producción de dióxido de carbono por consumo de combustibles fósiles» (http:/ / es.wikipedia.org/wiki/Antropog\%C3\%A9nico).

4 En 1968 Paul Ehrlich publicó el libro The population bomb, en el que señalaba los elementos negativos que trae consigo la sobrepoblación de nuestra especie. Treinta años después sigue sosteniendo las mismas tesis, e incluso agrega las implicaciones del consumo contemporáneo. Ver : http://e360.yale.edu/feature/too_many_people_too_much_consump-tion/2041/.
} 
bienes materiales, energéticos y alimenticios que hacen posible nuestro sostenimiento.

Indudablemente los seres humanos necesitamos recursos provenientes de la naturaleza para subsistir; sin embargo, la especie humana fue durante mucho tiempo poco consciente de la operatividad de los ecosistemas y del impacto que tienen las modificaciones antropogénicas en éstos (cambio de uso de suelo, contaminación, extracción excesiva de recursos, reducción o extinción de biodiversidad). En otras palabras, nuestra especie no ha respetado límites, y esto es en gran medida resultado de la creencia de que los bienes ecológicos son inagotables, y que la naturaleza tiene la capacidad de renovarse y regenerarse infinitamente.

Esa creencia ha sido desmentida recientemente ${ }^{5}$ y nos ha conducido a elaborar una autoevaluación y a formularnos algunas preguntas: ¿el mundo natural, y los seres que en él habitan, tienen algún valor que no sea necesariamente un valor instrumental a favor de nuestra especie? ¿Cómo podemos descubrir y argumentar que existen valores en el mundo natural que están más allá del reconocimiento que los seres humanos podemos hacer de ellos?

A lo largo de la historia se ha considerado a la naturaleza como un gran almacén que pone a nuestro alcance de manera gratuita sus «servicios ecosistémicos» $»^{6}$, para que los se-

\footnotetext{
5 En el Informe elaborado por el Club de Roma se señala «en un planeta limitado, las dinámicas de crecimiento exponencial (población y producto per capita) no son sostenibles». El planeta cuenta con recursos naturales no renovables, tierras de cultivo finitas y una capacidad de absorción de los productos contaminantes limitada. Así es que «si el actual incremento de la población mundial, la industrialización, la producción de alimentos y la explotación de los recursos naturales se mantiene sin variación, se alcanzarán los límites absolutos de crecimiento de la tierra durante los próximos cien años» (ver Meadows, 1972). 6 La Evaluación de los Ecosistemas del Milenio ha definido los servicios ecosistémicos como aquellos beneficios que la gente obtiene de los ecosistemas. Esos beneficios pueden ser de dos tipos: directos e indirectos. Se consideran beneficios directos la producción de
} 
res humanos podamos usarlos y beneficiarnos de ellos. Esta visión del mundo natural parceló el valor de los bienes naturales en dos: por una parte, sólo se consideró valioso aquello que favorecía a nuestra especie, y se fue aprovechando y explotando, en algunos casos, hasta su agotamiento ${ }^{7}$. Por otra parte, aquello que no se consideraba útil para los fines prácticos de consumo y producción se veía como un estorbo; ejemplo de ello son algunas zonas de pastizales, de manglares, de humedales, e incluso regiones desérticas, consideradas como espacios ociosos mientras no se obtuviera algún beneficio de éstas, es decir, mientras no se generara ningún tipo de capital mediante su explotación, lo que explica la constante irrupción y modificación humana en estas zonas para convertirlas en espacios rentables.

Fue necesario el desarrollo de las ciencias y de las ingenierías ambientales para que comenzara a investigarse y a explicar de manera más específica la interrelación que se da entre organismos en un ecosistema, y para reconocer las alteraciones y los daños que provocan muchas de las intervenciones humanas en ellos. Las investigaciones y los estudios realizados por estas disciplinas hicieron posible que empezara a entenderse la naturaleza de manera diferente, ya no sólo como un mecanismo sin ningún fin en sí mismo, sino como

provisiones -agua y alimentos (servicios de aprovisionamiento), o la regulación de ciclos como las inundaciones, degradación de los suelos, desecación y salinización, pestes y enfermedades (servicios de regulación). Los beneficios indirectos se relacionan con el funcionamiento de procesos del ecosistema que genera los servicios directos (servicios de apoyo), como el proceso de fotosíntesis y la formación y almacenamiento de materia orgánica; el ciclo de nutrientes; la creación y asimilación del suelo y la neutralización de desechos tóxicos. Ver: http://www.maweb.org/documents/document.439.aspx.pdf

7 Evidencias históricas muestran que el problema del agotamiento de recursos naturales no es reciente, éste ha acompañado a los seres humanos durante toda su historia. La diferencia es que en el pasado, los impactos ambientales sólo tuvieron repercusiones a nivel regional; en la actualidad, en cambio, es un problema global. Ver Hughes 1981. 
un conjunto de interacciones constantes entre todos los organismos que componen un ecosistema para alcanzar sus objetivos particulares y, a partir de éstos, su integridad ecosistemática.

La visión fragmentaria que se tuvo del mundo, por lo menos hasta finales de la década de 1960, fue catalogada como antropocéntrica, pues el único criterio empleado para valorar los objetos del mundo natural estaba asentado en función de la satisfacción, la utilidad o el bienestar que éstos pueden producir en las personas. Para hacer frente a esa manera parcial de ver el mundo natural, se propuso, en la década señalada, un cambio de perspectiva axiológica, es decir, hacer de lado el modelo antropocéntrico y pensar en uno biocéntrico o ecocéntrico que tomara en cuenta e incluyera, no sólo el bienestar de la especie humana, sino de todos los seres vivos, y en general de los ecosistemas. El bienestar de cualquier otro ser o entidad no humana, bajo el enfoque antropocéntrico, sólo tiene valor en la medida en que contribuye a algún beneficio humano, es decir, todo lo no humano sólo posee valor instrumental. Los enfoques biocéntrico y ecocéntrico, en cambio, lo que ponderan es la integridad de la naturaleza en general, la cual debe cuidarse y respetarse, independientemente del beneficio directo o indirecto que proporcionen a nuestra especie. Este valor especial y autónomo contenido en la naturaleza es denominado, por estas visiones, valor intrínseco.

\section{Del valor instrumental al reconocimiento del valor intrínseco en los entes no humanos}

La visión axiológica parcializada, a la que he hecho referencia, comenzó a ser cuestionada filosóficamente a partir de la 
década de 1970. La crítica a tal visión obedece básicamente a la idea de que los seres humanos tenemos deberes morales hacia el mundo no humano, que no se reconocieron ni consideraron en el pasado. Se han señalado como posibles causas de esta falta de consideración moral dos hechos: el primero, una arraigada tradición religiosa que sostiene la idea de que los seres humanos somos creaturas divinas y que, por mandato divino, tenemos el derecho y la obligación de someter el mundo y las creaturas que en él habitan ${ }^{8}$; el segundo hecho, que justifica las acciones de dominio hacia el mundo natural, es que los seres humanos somos la única especie con capacidad racional y lingüística, lo cual nos permite tener una clara consciencia de nuestra conducta moral, de acuerdo con lo establecido desde Aristóteles:

La razón de que el hombre sea un animal social más que cualquier abeja y que cualquier otro animal gregario, es clara. La naturaleza no hace nada en vano. Sólo el hombre, entre los animales, posee la palabra. La voz es una indicación del dolor y del placer; por eso la tienen también los otros animales. (Ya que por su naturaleza ha alcanzado hasta tener sensación del dolor y del placer e indicarse estas sensaciones unos a otros). En cambio, la palabra existe para manifestar lo conveniente y o dañino, así como lo justo y lo injusto. Y esto es lo propio de los humanos frente a los demás animales: poseer, de modo exclusivo, el sentido de lo bueno y lo malo, lo justo y lo injusto, y las demás apre-

\footnotetext{
8 Lynn White Jr. Publicó en 1967 el artículo titulado «The Historical Roots of Our Ecologial Crisis», en el que señala cómo históricamente los seres humanos han ido modificando el entorno natural en su propio beneficio con ayuda de la ciencia y de la técnica (occidental), perjudicando, consciente o inconscientemente, el equilibrio ambiental. Para White nuestra ciencia y tecnología están muy compenetradas de «arrogancia cristiana», de manera que ve en ellas el origen de nuestros problemas ambientales. Ver White, 2007. Relacionadas con esta crítica, puede consultarse también Passmore, 1978; y Callicott, 1993.
} 
ciaciones. La participación comunitaria de ésas funda la casa familiar y la ciudad (Política, 1253a).

Estas facultades naturales nos han convertido tradicionalmente en miembros de la comunidad moral, y nos han dotado además de un valor especial, denominado valor intrínseco, cuya característica principal es impedir cualquier tipo de instrumentalización o uso de nuestras personas como medio, es decir, gracias a ese valor obtenemos la garantía de que se nos trate con respeto y dignidad por «nuestro propio bien» $\mathrm{o}$ «por derecho propio»". En este sentido una persona no puede ser utilizada como «medio» para que otra alcance un fin. El valor de la misma no puede asentarse en la consideración «si me es útil, entonces es valiosa». De acuerdo con las teorías que defienden la existencia de este tipo de valor, las personas siempre deben valorarse como fines en sí mismas, nunca de manera instrumental ${ }^{10}$.

Decir que sólo los seres humanos poseemos este tipo de valor y, por tanto, que sólo nuestra especie es digna de consideración moral, generó desconcierto y preocupación en los primeros filósofos ambientalistas, debido al radical sesgo antropocentrista con el que se justificaba nuestra falta de res-

\footnotetext{
Platón y Aristóteles ya hacían referencia a la existencia del valor intrínseco. Su visión de este valor era hedonista, pues radicaba en las experiencias placenteras, primariamente sensuales, pero su valía aumenta si están acompañadas de la inteligencia. Este punto de vista ha sido acompañado a lo largo de toda la tradición filosófica occidental. Ver Zimmerman, Michael J., "Intrinsic vs. Extrinsic Value", The Stanford Encyclopedia of Philosophy (Winter 2010 Edition), Edward N. Zalta (ed.) URL= http://plato.stanford.edu/archives/win2010/ entries/value-intrinsic-extrinsic/.

10 La referencia clásica de este punto de vista es la empleada por Kant: «Los seres cuya existencia no descansa en nuestra voluntad, sino en la naturaleza, tienen, empero, si son seres irracionales, un valor meramente relativo, como medios, y por eso se llaman cosas; en cambio los seres racionales llámense personas porque su naturaleza los distingue ya como fines en sí mismos, esto es, como algo que no puede ser usado meramente como medio, y, por tanto, limita en ese sentido todo capricho (y es un objeto de respeto)» (1983; 82-83).
} 
ponsabilidad hacia todo lo no humano. Esta situación motivó a un importante número de filósofos a buscar, determinar y justificar las razones por las cuales algunas especies de animales no humanos y las entidades naturales, particular o colectivamente, merecen cierta consideración moral; asimismo, establecer qué facultades o características deben tener los entes naturales no humanos que puedan considerarse análogas al valor intrínseco que otorgamos a nuestra especie, lo cual nos obligaría a respetarlas de manera semejante, tal como lo hacemos con los miembros de nuestra comunidad moral -al menos en teoría.

a) Teorías sensocentristas

Las primeras reflexiones que se produjeron al respecto sostuvieron y siguen sosteniendo un sesgo utilitarista, ceñidas por la directriz marcada por Jeremy Bentham de que lo moralmente importante no es si un ser sabe razonar o sabe hablar, sino si es capaz de experimentar placer y dolor (ver Bentham, 1970; 283). Esta capacidad, antes que cualquier otra, debería ser suficiente para otorgar consideración moral a un gran número de animales no humanos. Sin embargo, lo que tradicionalmente se ha tomado como criterio para recibir consideración moral han sido las capacidades anteriormente señaladas: racionalidad y lenguaje. Peter Singer, filósofo de línea utilitarista, y principal promotor de la defensa del bienestar animal, señala que «si un ser sufre, no puede haber justificación moral alguna para negarse a tener en cuenta ese sufrimiento» (Singer, 1999; 44). Para él, los seres humanos tenemos el compromiso de expandir nuestro círculo moral, e incluir en éste a los animales (ver Singer, 1981). 
Siguiendo por esta línea, el filósofo californiano Tom Regan, promotor de la defensa de los derechos animales, señala que la capacidad de sentir es sólo un primer elemento a considerar en los juicios morales, pero no el único ni el último. Para él, los principales criterios con los que debemos evaluar nuestras acciones hacia los animales tienen que ver con que éstos sean «sujetos de una vida» (ver Regan, 2004; 1-120), lo cual incluye, además de la sensibilidad, ciertas facultades psicológicas y conscientes (percepción, memoria, vida emocional, conciencia temporal). Esto los dota además de un «valor inherente» que los seres humanos, en tanto que agentes morales (ver Regan, 2004; 130), debemos respetar y promover como un derecho básico de los animales, en su condición de pacientes morales.

\section{b) Teorías biocentristas}

Los enfoques anteriores dejan insatisfechos a los filósofos de giro biocentrista, como Paul W. Taylor y Kenneth Goodpaster, quienes están de acuerdo en que lo primero que debe hacerse para avanzar hacia una ética ambiental auténtica es eliminar el antropocentrismo, el cual se origina en la valoración instrumental que los humanos hacemos de la naturaleza y de los seres que en ella habitan; de ahí que estos filósofos señalen que deben modificarse los principios axiológicos antropocéntricos que guían a la ética, y elaborar unos de giro biocéntrico, los cuales deben fundarse en el bien propio que cada ser se esfuerza por realizar para sostener su vida, y el cual constituye el fundamento de su valor intrínseco.

Para Kenneth Goodpaster, ni «la racionalidad, ni la conciencia, ni la capacidad de experimentar placer y dolor son 
condiciones necesarias (aun cuando puedan ser suficientes) para recibir considerabilidad moral» $(2004 ; 149)$, para él la única condición es el hecho de «estar vivo», pues tanto plantas y árboles, al igual que cualquier ser sensible, pueden verse beneficiados o dañados con nuestras acciones; por tanto, son candidatos a tener considerabilidad moral. Para Paul W. Taylor, cada organismo es un centro teleológico de vida, «es algo que ha de realizarse como un fin en sí mismo» (2005; 11), es decir, un individuo persiguiendo su bien propio de un modo propio con base en sus propios intereses, de los cuales puede ser o no consciente; esto no implica que por falta de consciencia podamos hacer con él lo que nos venga en gana $^{11}$. Para Paul W. Taylor, los animales y las plantas que conforman los ecosistemas tienen "valía inherente», es decir, un valor que es independiente de cualquier valoración instrumental y ninguna referencia al bien de cualquier otro (ver Taylor, 1989; 71).

\section{c) Teorías ecocentristas}

Una vez que se ha llegado a este punto, puede continuarse su ampliación para integrar en este tipo de reflexión a la totalidad de los ecosistemas, los cuales pueden ser considerados también como portadores de valor intrínseco. A este enfoque se le denomina ecocéntrico, y sus principales representantes son Aldo Leopold, Holmes Rolston III y Baird Callicott.

Aldo Leopold sería el primer representante del giro ecocentrista, pues en su texto «La ética de la tierra» muestra claLas plantas y los árboles no tienen consciencia de aquello que les beneficia o perjudica,
esto no significa que, en tanto organismos vivientes, no tengan intereses y fines por realizar. 
ramente esta faceta, específicamente en el apartado «La pirámide de la tierra», en el que describe las diferentes formas en que la naturaleza se organiza a través de circuitos por los que fluyen todos aquellos elementos energéticos que hacen posible el funcionamiento y sostenimiento de las cadenas tróficas, las cuales mantienen con vida a nuestro planeta y a todos sus residentes, de manera que ningún elemento o entidad son centrales, sino que todos contribuyen para el buen funcionamiento de todo el sistema ${ }^{12}$.

Holmes Rolston, por su parte, desarrolló una teoría con la que intenta mostrar y justificar que la naturaleza posee su propio valor sistémico. Toma como base las propuestas de la ética biocéntrica, pero introduce un elemento adicional con el que enfatiza su particular punto de vista, más holista que el de las éticas anteriores: «Si vamos a respetar toda la vida, tenemos que cruzar aún otra frontera, la que hay entre la zoología y la botánica, entre la vida que siente y la que no» (2004; 75). Lo que Rolston quiere mostrar y enfatizar es que la vida no está presente únicamente en los seres individuales, pues anterior a ellos existen múltiples interrelaciones entre diversos organismos naturales bióticos y abióticos, los cuales hacen posible la vida individual, de manera que nuestra preocupación por el medio ambiente debe ser holística más que individual; se debe buscar la armonía y el equilibrio en los ecosistemas, aunque esto en ocasiones conlleve el sacrificio de individuos particulares (ver Rolston III, 2004; 81).

J. Baird Callicott (ver Callicot, 2004; 99-127) por su parte, intenta sintetizar los objetivos generales de la ética ambien-

\footnotetext{
12 Ver Leopold, 1949; 25-44. Otras teorías éticas ecocéntricas son elaboradas por varios representantes de la Ecología profunda (Deep Ecology). Una muestra suficiente de sus posiciones se encuentran en: Callicott, 1989.
} 
tal e indicar los posibles rumbos que pueden orientar a esta nueva disciplina. Él parte de la idea de que la ética ambiental puede verse de dos maneras: como una filosofía aplicada, en cuyo caso sólo se trataría de una ampliación de la reflexión ética a un nuevo problema; o como una disciplina esencialmente teórica cuya tarea es desarrollar una teoría del valor no antropocéntrica. Ésta es la postura defendida por Callicott la cual completa señalando que hay dos tipos de valoraciones, una instrumental cargadamente antropocéntrica, y otra que reconoce la existencia del valor intrínseco en los entes naturales, y es sobre ésta donde deben asentarse las bases de la ética ambiental. Callicott, por otra parte, considera que la ética ambiental debe ser ante todo holística, es decir, preocuparse por la integridad ecosistémica, antes que por la de los individuos o algunas especies, sean animales (liberación animal) u organismos vivientes en general (conativismo ético). Por último, Callicott apuesta por la formulación de una teoría ambiental única (monismo) que sirva para ofrecer una vía de resolución a los problemas ambientales, ya que considera que éstos no deben resolverse aplicando unas veces el utilitarismo y otras el deontologismo (pluralismo), puesto que ambas teorías son mutuamente contradictorias, lo cual genera desconcierto y desconfianza en las posibles soluciones ofrecidas por la ética ambiental para la resolución de los problemas (ver Callicott, 2005, 116-129).

Se puede concluir, a partir de lo dicho, que estas propuestas éticas comparten en común dos características básicas: en primer lugar, una visión antiantropocentrista, pues para los defensores de ellas la especie Homo sapiens no es la única que posee estados intrínsecamente valiosos, éstos 
están presentes de diversas maneras en el mundo natural ${ }^{13}$, tanto en los animales no humanos, como en las plantas y en los ecosistemas; en segundo lugar, que la existencia de todo ente natural importa sin que medie en ello ningún tipo de finalidad, utilidad práctica o estética para la satisfacción humana. Su valor intrínseco, por tanto, radica en el mero hecho de existir, y en que cada entidad natural alcance su plenitud de acuerdo con su propia naturaleza.

3. Más allá del valor intrínseco: el pragmatismo ambiental

Los intentos de edificar una nueva ética que cambiara y modificara nuestras actitudes antropocentristas, y que hiciera algunas aportaciones importantes para contribuir a disminuir la problemática ambiental, tomó la noción del valor intrínseco como principio rector de sus propuestas. De acuerdo con cada uno de los puntos de vista ético-ambientales, el valor intrínseco puede encontrarse en la capacidad sensible (sensocentrismo), en el mero hecho de estar vivo (biocentrismo), o por formar parte de la naturaleza y desempeñar en ella una función esencial para el sostenimiento de todo el ecosistema (ecocentrismo).

Cada una de estas propuestas, aunque valiosas en sí mismas, no contribuyeron a poner en claro cómo enfrentar y resolver los problemas ambientales reales que como especie hemos generado, pues se quedaron atrapadas, desde el punto de vista de los filósofos ambientalistas pragmáticos, en un discurso me-

13 Entiéndase por mundo natural todo aquello que no es biológicamente humano ni producto humano. Ver Passmore, 2004; 263. 
tafísico que no logró ocupar un lugar importante en los ámbitos social y político, de manera que se consiguiera algún tipo de cambio real en las actitudes de las personas, o en las decisiones políticas relacionadas con los problemas ambientales.

Las principales críticas del pragmatismo ambiental hacia las propuestas ético-ambientalistas que le precedieron son tres: la primera de ellas está dirigida hacia la obstinación en querer fundamentar la idea de que todo ser natural posee valor intrínseco (o inherente), y pretender justificar por medio de éste por qué todo ser natural es digno de consideración moral. La segunda se dirige a la pretensión de suplantar la visión antropocéntrica por una antiantropocéntrica, que despoje al hombre de la supremacía que se ha autootorgado, y en su lugar elaborar una nueva ética biocéntrica o ecocéntrica que amplíe el círculo de consideración moral a un número mayor de especies, o a la totalidad de seres presentes en cada ecosistema, sin que ésta esté centrada en intereses y fines netamente humanos. La tercera es que el tipo de reflexión ética que se realizó no ofrece respuestas ni soluciones a los problemas reales.

Comencemos con los argumentos que critican la primera propuesta. Para los filósofos de línea pragmatista, no existe como tal algo que pueda decirse que es el valor intrínseco y que pueda aceptarse como verdadero. Para los pragmatistas, la función principal del pensamiento es ayudarnos a establecer relaciones satisfactorias con el entorno, interpretarnos dentro de las circunstancias concretas y, a partir de ellas, establecer los fundamentos de nuestras acciones, los cuales no pueden ser ajenos a las situaciones particulares. Las verdades como creencias surgen en la experiencia vital de sus protagonistas, no tienen una validez autónoma o a priori, sino que ésta se deriva de la práctica. De acuerdo con Charles 
Sanders Pierce «el hombre actúa conforme a su creencia en la medida en que su creencia tenga consecuencias prácticas» $(1978 ; 79)$, o, en palabras de William James, «un significado que no sea práctico es, para nosotros, como si no existiera» (2002; 48). Pretender entonces que se acepte como verdad que algo posee en sí mismo un cierto valor intrínseco, sin que ese algo tenga para la persona algún significado práctico, o represente algún tipo de valor específico dentro de su propio contexto, va en contra de la visión pragmatista. Esto se vería más como un modo de imponer una cierta creencia, y el deseo de que ésta sea aceptada fiel y acríticamente, tal como lo supondría la tradición racionalista, y a la cual critica férreamente William James en su libro Pragmatismo:

El racionalismo es siempre monista. Parte del todo y de las ideas universales y se preocupa mucho de la unidad de las cosas. El empirismo comienza en las partes y hace del todo una colección, no sintiendo por tanto aversión a llamarse pluralismo [...]. El pragmatismo vuelve su espalda de una vez para siempre a una gran cantidad de hábitos muy estimados por los filósofos profesionales. Se aleja de abstracciones e insuficiencias, de soluciones verbales, de malas razones a priori, de principios inmutables, de sistemas cerrados y pretendidos «absolutos» y «orígenes». Se vuelve hacia lo concreto y adecuado, hacia los hechos, hacia la acción y el poder $(2002 ; 15)$.

Teniendo como fondo esta perspectiva, se comprende por qué para los pragmatistas una valoración ética, verdadera y correcta, debe estar basada en su utilidad real, en los resultados que se obtengan con la práctica de las reglas establecidas por la misma, cuyos objetivos estén orientados a la realización de cosas que vayan en pro de la colectividad. Al 
respecto, señala William James: «La verdad es el nombre de cuanto en sí mismo demuestra ser bueno como creencia y bueno también por razones evidentes y definidas» $(2002 ; 61)$.

Vale la pena aclarar que el éxito o la utilidad, a las que se hacen referencia en la visión de los pragmatistas, y que debe conducir a la verdad, el bien o lo valioso, no debe entenderse que tenga como objetivo la satisfacción o conveniencia personal. John Dewey aclara esta falsa idea elaborada por los críticos del pragmatismo de la siguiente manera:

Un concepto de la verdad que hace de ella un simple instrumento de ambición y exaltación privada es tan repulsivo que causa asombro que haya habido críticos que han atribuido ese concepto a unos hombres en su sano juicio. En realidad, la verdad como utilidad significa servicio para contribuir a la reorganización de la experiencia que la idea o la teoría proclama que es capaz de realizar. No se mide la utilidad de una carretera por el grado en que se presta a los designios de un salteador de caminos. Se mide por cómo funciona en la realidad como tal carretera, como medio fácil y eficaz de transporte y de comunicación pública. Lo mismo ocurre con la aprovechabilidad de una idea o de una hipótesis como medida de su verdad $(1993 ; 169)$.

La ética pragmática pretende ser una guía colectiva que, sin basarse en ningún principio moral ya establecido, sino sustentada en la idea de la utilidad de las cosas, fundamente que el valor de éstas reside en los resultados que puedan ofrecer. De esto se desprende que, para el pragmatista, el todo es más que la suma de las partes, y que lo general es más valioso que lo particular. Por tanto, para una ética pragmatista los juicios de valor y el saber colectivo de una comunidad cuentan con una mayor estima que la sabiduría de cualquier individuo 
de la misma. Además, un hombre auténticamente pragmático dará fundamento a sus juicios morales, teórica y prácticamente, acerca de lo que es mejor para el mayor número de personas. Esto significa que el pragmatista intenta lograr «el mayor bien para la mayoría», lo que se traduce en una búsqueda de prosperidad, armonía y felicidad, ideales que sólo se materializan en una sociedad por medio de una práctica correcta de normas morales que la misma sociedad elabora con base en sus intereses y necesidades.

El pragmatismo ambiental, a partir de estas directrices, destina su crítica al intento, ya referido de los primeros eticistas ambientales, de elaborar ciertas modificaciones en la ética (o más aún, fundar una nueva ética) a partir de un cambio en nuestras valoraciones hacia el mundo natural. Sin embargo, ninguna de las teorías elaboradas ha logrado, a los ojos de los pragmatistas ambientales, conseguir alguna modificación importante. Así lo señala Bryan Norton: «La ética ambiental ha estado dominada durante sus primeros veinte años por cuestiones de axiología, ya que los especialistas se han dedicado sobre todo a buscar un pequeño conjunto de principios coherentes que guíen la acción ambiental» (Norton, 2003; 117). Esos principios -señala Norton- tienen como objetivo ser unos «primeros principios» que puedan dar una única respuesta a cada dilema moral, y también justificar cualquier directiva moral que se derive de ellos. Esto, a su vez, conduce a una «simplificación axiológica», la cual da como resultado un «monismo moral», cuya tesis es que «una sola teoría es suficiente para sustentar un único juicio moral correcto en cada situación» (Norton, 2003; 117).

Lo anterior conduce a alguna forma de reduccionismo mediante el cual se intenta analizar todo asunto moral a través de la óptica de una teoría única. Éste ha sido el caso en la 
discusión que se ha sostenido en la ética ambiental, pues al evaluar qué debe valorarse y cómo, las opciones se reducen básicamente a dos posturas axiológicas: «o bien el valor de la naturaleza es enteramente instrumental para los objetivos humanos, o bien los elementos de la naturaleza poseen 'bienes en sí' (un valor que no depende de las valoraciones humanas)» (Norton, 2003; 119).

Podría parecer que el pragmatismo se ubica en el primero de estos casos, y podría asociársele justamente con lo que la ética ambiental pretende combatir: un antropocentrismo cuya visión del mundo es meramente instrumentalista. En opinión de Anthony Weston (ver 1996; 285), una teoría de los valores, desde el punto de vista pragmático, no está comprometida con un antropomorfismo ni con ninguna forma de éste, pues el rechazo pragmatista hacia la axiología ambiental que se vino construyendo parte de una crítica a la visión que ésta tiene de juzgar el valor de las cosas a partir de una concepción medios-fines últimos, estableciendo éstos como fines fijos e inherentes al objeto, lo cual conduce a un naturalismo axiológico ${ }^{14}$. Para la visión pragmatista, en cambio, los valores del mundo, de la sociedad y de las cosas, no son algo inherente a ellos, sino que es el sujeto (única especie capaz de valorar tanto en sentido epistemológico como ético) el que establece, dentro de ciertos patrones o límites culturales, sus propios criterios para valorar las cosas.

Lo anterior no significa que como los seres humanos somos los únicos capaces de hacer valoraciones, sólo nosotros

\footnotetext{
14 Lo que esta corriente filosófica sostiene es que el fundamento de lo que valoramos como bueno está asentado en algún tipo de propiedad que no se encuentra en nuestra conciencia, sino en el mundo natural, es decir, que los valores son una propiedad constitutiva de los hechos mismos, y los seres humanos nos limitamos a captarla.
} 
tengamos valor o seamos objetos únicos y últimos de valoración. En palabras de Weston: «El subjetivismo no implica una especie de sujeto-centrismo. Nuestros valores actuales pueden ser mucho más complejos y orientarse mucho más al mundo» (1996; 285). Para este filósofo, más que estar preocupados por una fundamentación que autojustifique el valor de los entes naturales, lo que debemos hacer es tratar de ubicar sus funciones y sus interdependencias dinámicas dentro de sus propios contextos, comprender las variadas formas de vida existentes, y con ello reconocer una pluralidad de valores concretos, permitiendo así una valoración más flexible y justa en cada situación.

Otra cuestión con la que no están de acuerdo los pragmatistas ambientales es con el antiantropocentrismo, propuesto por el biocentrismo y el ecocentrismo. El problema de este punto de vista, afín en ambas posturas, es que parten del prejuicio según el cual el antropocentrismo es inevitablemente explotador, instrumentalista y antiecológico. Sin embargo, como lo hace notar la Dra. Teresa Kwiatkowska:

La efectividad de una política ambiental no se reduce a cambiar de una percepción antropocéntrica a una orientada hacia la naturaleza. Conviene recalcar que una nueva visión ética del entorno natural consistirá precisamente en el intento de situarla en el contexto de las economías regionales, las políticas locales y las demandas exteriores, todas ellas incorporadas en un escenario social y cultural $(2008 ; 157)$.

Como se ha señalado ya, para el pragmatismo el ser humano concreto, es decir el individuo, se erige como centro de sus proyectos y de sus determinaciones, él es el principal promotor y constructor de sus ideas y sus acciones, lo cual lo hace simultáneamente responsable de las consecuencias de éstas. 
Concretamente, en el momento actual, los seres humanos debemos asumir la responsabilidad de los problemas ambientales que hemos ocasionado, y con ello los potenciales riesgos que esto conlleva ${ }^{15}$, los cuales muestran evidencia cada vez patente de hacerse presentes si no comenzamos a generar un cambio en nuestra cosmovisión, así como en nuestras actitudes y conductas hacia el mundo natural.

Al parecer hay un acuerdo generalizado de que la conducta humana hacia el medio ambiente no ha sido correcta ni mucho menos prudente, pues los intereses humanos, regidos básicamente por valores económicos, han sacrificado el equilibrio ambiental de nuestro planeta, a cambio de un bienestar humano distorsionado en muchos sentidos, pues los seres humanos no nos hemos conformado con obtener de la naturaleza sólo aquellos bienes necesarios para satisfacer nuestras necesidades básicas, éstas han pasado incluso a un segundo o tercer plano, pues el consumo inconsciente y descontrolado se ha convertido en la base de nuestras sociedades contemporáneas. El elemento negativo de esta disfuncionalidad es que «la actitud inherente al consumismo es devorar todo el mundo» $(1978 ; 43)$ indica Erich Fromm. A pesar de este notable hecho, el consumismo es alentado para hacer crecer el Producto Interno Bruto (PIB), y el incremento porcentual de éste se ha convertido en la medida principal para calcular el progreso y bienestar social.

15 El principal problema ambiental actualmente es la elevación de la temperatura promedio del planeta. Éste es provocado principalmente por el uso excesivo de combustibles fósiles y la deforestación. Si la temperatura sigue aumentando se incrementarán y se harán cada vez más intensos algunos fenómenos climáticos, entre los que destacan los huracanes, tornados y sequías. Puede verse el documental «Seis grados que podrían cambiar el mundo», de National Geographic. 
Por tanto, más que sobreponer una visión metafísica naturalista a nuestro antropocentrismo, lo que tenemos que hacer es replantear los principios básicos de nuestra conducta, de manera que estén más acordes con situaciones actuales reales concretas. Esto es precisamente lo que plantea el filósofo australiano Bryan Norton, propuesta que revisaré a continuación.

\section{Visión antropocentrista débil o moderada}

Los pragmatistas ambientales no comparten la idea de que un antiantropocentrismo ambiental, que critica y pretende obstruir los intentos de remediar los daños ocasionados a la naturaleza por nuestra especie, sea la solución que pueda favorecer un cambio en nuestra relación moral con el mundo natural; pero, tampoco creen que el antropocentrismo tradicional, que sólo valora moralmente a las personas, sus acciones y productos, sea el camino indicado. Lo que los pragmatistas ambientales proponen teóricamente, e intentan que los responsables de la gestión ambiental pongan en práctica, es un antropocentrismo débil o moderado.

Esta designación fue acuñada por Bryan Norton (ver 1984) para distinguir las diferencias entre un «antropocentrismo fuerte» (strong anthropocentrism) y un «antropocentrismo débil» (weak anthropocentrism). La característica principal del primero es que lo que se considera valioso toma básicamente como referencia la satisfacción de las preferencias sentidas (felt preference), identificadas por él como «los deseos o necesidades de individuos humanos, que al menos temporalmente, pueden ser satisfechas mediante una experiencia específica de los mismos» $(1984 ; 134)$. Estas preferencias y su 
satisfacción se imponen sobre las de cualquier otra especie ${ }^{16}$, sin que medie en ellas ningún tipo de consideración moral de las implicaciones causales de las acciones humanas. Un antropocentrismo débil se caracteriza, en cambio, por una visión más amplia del mundo, orientada por otro tipo de consideraciones a las cuales nombra Norton «preferencias ponderadas» (considered preference). Éstas son ciertas posturas que adopta la persona antes de actuar y aluden a «los deseos o necesidades que podrían ser expresados tras una cuidadosa deliberación, incluidos los juicios donde los deseos o necesidades son coherentes con una determinada visión del mundo; visión que, en cuanto tal, incluye teorías científicas y un marco metafísico que las interprete como expresión de ideales estéticos y morales» (Norton 1984; 134).

A partir de esta distinción, Norton indica en qué consiste la diferencia que distingue un antropocentrismo fuerte de un antropocentrismo débil:

Una teoría del valor es antropocéntricamente fuerte si todo el valor mostrado se explica por referencia a la satisfacción de las preferencias sentidas de los individuos humanos. Una teoría del valor es antropocéntricamente débil si todo el valor mostrado se explica por referencia a la satisfacción de alguna preferencia sentida de un individuo humano, la cual se extiende sobre los ideales existentes como elementos de una visión esencial del mundo para la determinación de preferencias consideradas (1984; 134).

De acuerdo con lo dicho por Norton, las preferencias sentidas pueden ser racionales o no. Las preferencias pondera-

\footnotetext{
16 Este modo antropocentrista de ver el mundo ha sido calificado como déspota o chovinista; ver R. Routley y V. Routley 1979, y Passmore 1998.
} 
das, en cambio, son resultado de una reflexión meticulosa y concuerdan con una previa visión del mundo. El peligro de todo antropocentrismo fuerte para Norton, de acuerdo con la interpretación de la filósofa ibérica Carmen Velayos, «reside en su incapacidad para poner en cuestión las preferencias sentidas de los individuos, pues impide la discriminación entre sistemas de valor explotadores de la naturaleza y otros que no lo sean» $(1996 ; 68)$. Esta falta de ponderación es la que lleva a las personas a actuar sin marcos de referencia ambientales, y a conducirse regidas por principios inmediatos de consumo, guiadas únicamente por fines instrumentales sin reconocerle a la naturaleza ningún derecho o prerrogativa; también, es la razón por la cual los grandes productores no se detienen ante nada: talan bosques, secan pantanos, modifican el curso de los ríos, no les preocupa socavar los ecosistemas hasta su destrucción. Bryan Norton considera injustificables todas estas prácticas que son auspiciadas por el antropocentrismo fuerte o radical.

El antropocentrismo débil, por el contrario, proporciona una base para criticar el sistema de valores que ve a la naturaleza sólo como un objeto de explotación, pues ofrece dos recursos éticos de importancia fundamental para el ecologismo. Primero, enfatiza la estrecha relación existente entre la especie humana y otras especies, lo cual sirve de base para criticar las preferencias que sólo valoran a la naturaleza y los animales no humanos instrumentalmente. En segundo lugar, reconoce que las experiencias humanas sirven de base para la formación de valores críticos. Ambos recursos permiten remplazar las preferencias sentidas por otras más racionales, y por medio de ellas valorar la naturaleza, no sólo como un almacén que nos ofrece sus servicios, sino que podemos descubrir en ella valores transformativos (transformative values) 
que modifican nuestros criterios axiológicos, de manera que la naturaleza ya no es vista sólo como un simple satisfactor de valores fijos y de consumo, sino que llega a ser también una importante fuente de inspiración en la formación de valores, «como una maestra de valores humanos» (nature takes on value as a teacher of human value $)^{17}$.

Bryan Norton, por otra parte, no comparte la idea de aquellos que creen que una ética ambiental deba construirse sobre bases no antropocentristas, y cuyos criterios para fundamentarla se sostengan en la creencia de ciertos valores intrínsecos en el mundo natural, los cuales existen independientemente de toda valoración humana; pues, aun cuando esto fuera posible, y pudiéramos hablar del valor de otras entidades, los que prescribirían qué es valioso y por qué, serían los seres humanos; por tanto no se estaría eliminando el antropocentrismo. Lo que sí puede ocurrir, tal y como lo defiende Norton, es que los seres humanos elaboremos una mejor y más amplia ponderación axiológica del mundo natural que no esté centrada únicamente en las preferencias humanas, sino que se enfoquen y consideren también otros valores. Esto requerirá

17 Si tomamos como referencia la figura de la naturaleza como una maestra -o como madre (Gaia)-, tenemos que aceptar que no podemos ser los seres humanos los que de manera caprichosa dictemos los lineamientos a los que ella debe someterse, que sea ella la que se ajuste a nuestras leyes (científicas) y no nosotros a sus principios (naturales). Tenemos que dejar ya de hacer travesuras, sentarnos y escucharla, poner atención a lo que tiene que decirnos y a sus advertencias. Si el planeta tiene fiebre y está aumentando su temperatura, ésta es la mayor advertencia que puede hacernos de su padecimiento y de que urge hacer algo, buscar soluciones que alivien su malestar. Nosotros estamos dentro de ella y no somos ajenos a los escenarios que se pronostican. En relación con esto flotan en el ambiente social dos posturas, una optimista y otra pesimista fatalista. En la primera se ubican las personas que creen que los problemas ambientales son reversibles si hacemos algo; en la segunda están todos aquellos que creen que ya no hay solución ante los graves problemas ecológicos, y consideran que la única manera en que nuestro planeta puede sobrevivir es que la humanidad desaparezca, e inicie un nuevo ciclo evolutivo en este planeta; por tanto, no están dispuestos a modificar sus costumbres, «ipara qué?», antes bien, están resignados a que algún día se llegará a un estado fatal irreversible para nuestra especie. Ver Schifter \& González-Macías, 2005. 
el reconocimiento de la variedad y diversidad de funciones que llevan acabo todos los entes naturales, razón por la cual existen, y cuya existencia no está supeditada a beneficiar exclusivamente a la especie humana, sino a su entorno, con el cual colaboran para que exista en él un equilibrio ecológico. Utilizaré un ejemplo para ilustrar lo dicho. Tradicionalmente se valoró a las abejas por su miel y la cera, y se ignoró o se ponía poco interés en otra función que desempeñan y que es incluso más importante en términos ambientales: la polinización ${ }^{18}$. Esta actividad no es exclusiva de las abejas, sino que es compartida por una cantidad indeterminada de insectos, $\mathrm{e}$ incluso algunas aves. Sin embargo, los seres humanos, utilizando como único criterio el valor económico de sus productos agrícolas (felt preference), han sostenido una implacable e incesante lucha para controlar, y en la medida de lo posible exterminar mediante plaguicidas, todos aquellos insectos que puedan arruinar su productividad comercial ${ }^{19}$. Una teoría del valor centrada en un antropocentrismo débil, por el

\footnotetext{
18 El $90 \%$ de las plantas del planeta requieren de un agente externo para reproducirse, ya que, a diferencia de los animales, no se pueden mover. De los polinizadores depende la producción de casi todos los frutos que comemos. La polinización podría hacerse manualmente, sólo que sería una labor terriblemente grande y millonaria, porque hay que hacerlo flor por flor para que dé fruto y, si queremos tener millones de frutos, hay que hacerlo millones de veces. Los polinizadores son servidores ambientales importantes para mantener la biodiversidad y lograr un alto rendimiento agrícola. Si se continúan realizando acciones que representen una amenaza para los polinizadores, e.g., a través del uso intensivo de plaguicidas, se pondrá en grave riesgo la existencia de éstos y la de nosotros al quedarnos sin este servicio ambiental. Ver: http:/ / www.jornada.unam.mx/2009/01/13/index.php?s ection $=$ ciencias $\&$ article $=\mathrm{a} 02 \mathrm{n} 1$ ciencia

19 Rachel Carson, en su obra Primavera silenciosa, advirtió los peligros y las consecuencias que estas prácticas ocasionaban en el ambiente y en la cadena alimenticia, pues no sólo se provocaba la muerte de los insectos dañinos para los cultivos, sino en general de todo insecto sin importar si era o no perjudicial, pero, además, al ser éstos el alimento básico de las aves, éstas también morían de envenenamiento, y progresivamente se iba ocasionando un daño en la cadena alimenticia, hasta llegar incluso a provocar problemas de salud en nuestra propia especie. Además, la muerte de las aves, producto de estas prácticas, da como resultado una primavera silenciosa, pues priva al bosque del canto de las aves, y con ello se pierde ese elemento estético característico de estos lugares.
} 
contrario, deberá elaborar una ponderación de estos métodos, y de todo sistema de producción que sólo considere el bienestar humano, sacrificando éste en los ecosistemas y los seres vivos que lo habitan, y poniendo en riesgo su permanencia y supervivencia. Tal ponderación deberá basarse en criterios científicos y estéticos que ayuden a explicar y justificar las razones por las que nuestra relación con la naturaleza, y los seres vivos que en ella se encuentran, debe ser más responsable y estar marcada con un claro sentido ético. De esta manera, no sólo se estará tomando en cuenta el bienestar humano, sino se considerará también, bajo un cierto holismo ambiental, el bienestar de toda la comunidad biótica a la que ya hacía referencia Aldo Leopold en su artículo «La ética de la tierra», indicándolo de la siguiente manera:

Dejemos de pensar en el uso decente de la tierra tan sólo como un problema económico. Examínese cada interrogante en términos de lo que ética y estéticamente es correcto, así como económicamente conveniente. Una cosa es correcta cuando tiende a mantener la integridad, la estabilidad y la belleza de la comunidad biótica; y es incorrecta cuando tiende a hacer lo contrario $(2004 ; 76)$.

Por otra parte, Bryan Norton propone que una ética ambiental responsable debe dejar atrás los problemas ontológicos y la búsqueda de una teoría unificada en materia de valores ambientales -desarrollados ambos por los biocentristas y los ecocentristas-, pues, a pesar de los años que llevan estancados en esa discusión, no han llegado a ningún consenso y han perdido la oportunidad de ofrecer consejos prácticos y de utilidad a los responsables de organizar y administrar las políticas ambientales. En sus palabras: 
El problema real de la ética ambiental -pienso yo, en tanto pragmatista- es lograr en las sociedades democráticas políticas más razonables que cuadren con los intereses humanos, políticas que protejan la naturaleza y los procesos naturales en concordancia con nuestro mejor conocimiento científico y, asimismo, que reduzcan la incertidumbre y hagan prosperar nuestro conocimiento para abordar problemas y decisiones de administración en el futuro [...] En consecuencia, yo hago mucho menos hincapié en los problemas ontológicos de Callicott y más en el problema epistemológico de determinar (a) cómo construimos modelos de sustentabilidad que protejan realmente toda la gama de los valores humanos en un futuro indefinido y (b) cómo desarrollamos una conciencia social que cree en las sociedades democráticas, mejores procesos para abordar decisiones ambientales que afectan al interés público y, de esa manera, transitar hacia políticas consistentes con (a) (2003; 132-133).

Norton reconoce que es necesario construir modelos ontológicos que defiendan todos aquellos valores necesarios para crear modelos sustentables en los que se incluya también el tipo de rango moral de otras especies, sin importar-desde mi punto de vista- que esto se justifique a través del otorgamiento de un cierto valor inherente que existe de forma independiente, tanto en los individuos humanos como en ciertas especies del mundo natural. Sin embargo, una vez hecho esto, debe superarse el nivel ontológico junto con sus pretensiones monistas-universalistas, y diseñar teorías que proporcionen «tanto una teoría del valor como una justificación epistemológica a afirmaciones de prioridad» (Norton, 2003; 133). Es decir, la justificación ontológica del valor es importante, pues debe partirse del reconocimiento de que los valores existen, pero de esto no se sigue que todo tenga el mis- 
mo valor, o que un único principio sirva para justificar el valor de todas las cosas, más aún, pensar que algo posea el mismo valor sin distinguir su prioridad en situaciones distintas ${ }^{20}$.

Hay que señalar que la crítica de Norton a la ética ambiental tradicional es básicamente un reclamo a su falta de apertura a los problemas y soluciones reales; es, por ello que, para él, lo más importante no es tanto la justificación filosófica de los valores y principios que deben regir la ética ambiental, sino la aplicación práctica de ellos en la problemática real ${ }^{21}$. A Norton lo que le interesa es armar a los ambientalistas con principios morales auténticos y defendibles que respondan a situaciones reales y específicas, que puedan argumentar y justificar por medio de tales principios: e.g., por qué es necesaria la preservación, conservación o restauración de algún sitio en particular, $\mathrm{u}$ otros temas recurrentes en las agendas de los ambientalistas. En sus propias palabras:

[...] parece probable que dichos ambientalistas alcancen logros mayores apelando a la idea intuitiva y relativamente no controvertible de que la utilización de los recursos naturales implica la obligación de protegerlos para futuros usuarios -una teoría de la sustentabilidad basada en la equidad intergeneracional-, más que haciendo apelaciones exóticas a valores inherentes que se en-

\footnotetext{
20 Por ejemplo, podemos decir que el agua potable es intrínsecamente valiosa, pero la valoración de este recurso es diferente cuando es escasa o se está agotando, que cuando es abundante. Es una prioridad hacer un uso responsable de ella en el primer caso, en tanto que en el segundo caso es irrelevante cómo se use y la cantidad que se use. Lo importante será convencer a los del segundo caso de asumir la responsabilidad de su uso, especialmente en estos tiempos. Sirva como ejemplo el artículo de Sofía Jarrín «El agua como tema de seguridad nacional». Ver: http://www.ecoportal.net/Temas_Especiales/Agua/El_Agua_ como_Tema_de_Seguridad_Nacional

21 Para un análisis más completo acerca de los dilemas que enfrentan los ambientalistas, ver Norton 1991.
} 
cuentran en la naturaleza y que hasta ahora nadie había notado $(2003 ; 134)$.

En suma, lo importante para Norton es que los eticistas ambientales busquen problemas reales y propongan soluciones a través del ofrecimiento de consejos prácticos y útiles en forma de claras directivas de administración, aplicables a problemas complejos y controvertidos en la planeación y administración ambiental, más que estar elaborando «dilemas metafísicos acerca de qué o quién posee su propio valor» (Norton, 2003; 136).

\section{BIBLIOGRAFÍA}

Aristóteles. (1988). Política. Madrid: Gredos.

Bentham, J. (1970). An Introduction to the Principles of Morals and Legislation. London: The Athlone Press.

Callicott, J. B. (2005). «Holistic Environmantal Ethics and the Problem of Ecofacism». En Zimmerman, Michael E. et al., Environmental Philosophy. From Animal Rights to Radical Ecology, Upper Saddle River, M. J.: Pearson. Prentice Hall.

. (2004). «Teoría del valor no antropocéntrica y ética ambiental. En Valdés (2004).

. (1993). «En busca de una ética ambiental». En: Kwiatkowska, T. \& J. Issa (1998); 85-160.

. (1989). In Defense of the Land Ethic: Essays in Environmental Philosophy. Albany: State University of New York Press.

Dewey, J. (1993). La reconstrucción de la filosofía. México: Planeta-Agostini, México. 
Esquivel, L. (2006). Responsabilidad y sostenibilidad ecológica. Una ética para la vida. Tesis Doctoral. Barcelona: Universidad Autónoma de Barcelona, Facultad de Filosofía y Letras, 2006.

Fromm, E. (1978). ¿Tener o ser? México: FCE.

Goodpaster, K. (2004). «Sobre lo que merece consideración moral». En: Valdés (2004).

Hughes, D. (1981). La ecología en las civilizaciones antiguas. México: FCE.

James, W. (2002). Pragmatismo. Un nuevo nombre para algunos antiguos modos de pensar. Barcelona: Folio.

Kant, I. (1983). Fundamentación de la metafísica de las costumbres. Madrid: Espasa Calpe.

Kwiatkowska, T. (2008). Controversias de la ética ambiental. México: UAm \& Plaza y Valdés.

Kwiatkowska, T. \& J. Issa (comps). (2003). Los caminos de la ética ambiental, vol. II. México: CONACYT \& Plaza y Valdés \& UAM.

. (eds). (1998). Los caminos de la ética ambiental: una antología de textos contemporáneos. México: Plaza y Valdés. Leopold, A. (2004). «Ética de la tierra». En: Valdés (2004).

Meadows, D. H. (1972). Los límites del crecimiento. Informe al Club de Roma sobre el predicamento de la humanidad. México: FCE.

Norton, B. (2003). «Por qué no soy no-antropocentrista: Callicott y el fracaso del inherentismo monista». En: Kwiatkowska, T. \& J. Issa (2003).

. (1991). Toward Unity among Environmentalists. New York: Oxford University Press.

. (1984). «Environmental Ethics and Weak Anthropocentrism». Environmental Ethics, Vol. 6, No. 2; 131-148. 
Passmore, J. (2004). «Actitudes hacia la naturaleza». En: Valdés (2004).

. (1998). «El hombre como déspota». En: Kwiatkowska, T. \& J. Issa (1998); 167-192.

. (1978). La responsabilidad del hombre frente a la naturaleza. Madrid: Alianza Editorial.

Peirce, Ch. S. (1978). Lecciones sobre el pragmatismo. Buenos Aires: Aguilar.

Regan, T. (2004). The Case for Animal Rights. Berkeley: University of California Press.

Rolston III, H. (2004). «Ética ambiental: valores en el mundo natural y deberes para con él». En: Valdés (2004).

Routley, R. \& V. Routley. (1979). «Against the Inevitability of Human Chauvinism». En: Goodpaster, K. E. \& K. M. Sayre (eds.), Ethics and Problems of the 21 $1^{\text {st }}$ Century (pp. 36-59), London: University of Notre Dame Press.

Schifter, I. \& C. González-Macías. (2005). La tierra tiene fiebre.

México: FCE \& SEP \& CONACYT.

Singer, P. (1999). Liberación animal. Madrid: Trotta.

. (1981). The Expanding Circle. Princeton: Princeton University Press.

Taylor, P. (2005). La ética del respeto a la naturaleza. México: UNAM-IIF.

. (1989). Respect for Nature. A Theory of Environmental Ethics. Princeton: Princeton University Press.

Valdés, M. (comp). (2004). Naturaleza y valor. Una aproximación a la ética ambiental. México: UNAM \& FCE.

Velayos, C. (1996). La dimensión moral del ambiente natural: ¿necesitamos una nueva ética? Madrid: Ecorama.

Weston, A. (1996). «Beyond Intrinsic Value: Pragmatism in Environmental Ethics». En Light, A. \& E. Katz (eds.), Environmental Pragmatism. London: Routledge. 
White, L. (2007). «Raíces históricas de nuestra crisis ecológica». En: Ambiente y desarrollo 23 (1); 78-86. [Original: (1967). "The Historical Roots of Our Ecological Crisis», Science 155; 1203-1207]. 


\section{RESUMEN}

La ética ambiental hace su aparición en la década de 1970. Surge con la intención de evaluar desde un ámbito propiamente filosófico la relación del hombre con la naturaleza desde el punto de vista de la ética. Esta disciplina, al igual que la filosofía en su conjunto, se ha ido desplegando en diversas concepciones que tratan de entender y explicar, desde diversos enfoques, el comportamiento moral de las personas respecto del mundo natural. Mi intención en este trabajo no es hacer un análisis de estas posturas, sino presentar algunas de las críticas que se han hecho recientemente, desde el punto de vista del pragmatismo ambiental, a las maneras y métodos adoptados en el quehacer de la ética ambiental, los cuales, vistos desde el pragmatismo, se quedaron atrapados en discusiones académicas metaéticas, ocasionando con ello una pobre o nula evaluación de los problemas ambientales reales, así como propuestas viables de resolución en casos de conflicto.

Palabras clave: ética ambiental; antropocentrismo; pragmatismo; Bryan Norton; Aldo Leopold.

\section{ABSTRACT}

Environmental ethics makes its appearance in the 1970s, up in order to evaluate properly philosophical field from a man's relationship with nature from the point of view of ethics. This discipline, like philosophy as a whole, has been deployed in various concepts that seek to understand and explain, from several perspectives, the moral behavior of people about the natural world. My intention in this paper is 
not to analyze these positions, but to present some of the criticisms that have been made recently, from the point of view of environmental pragmatism, to the ways and methods adopted in the work of environmental ethics, which, seen from pragmatism, were stuck in metaethical academic discussions, thereby causing poor or no assessment of actual environmental problems and viable proposals in cases of conflict resolution.

Key words: environmental ethic; anthropocentrism; pragmatism; Bryan Norton; Aldo Leopold. 